\title{
Effects of leptin on leptin receptor isoform expression and proliferative activity in human normal prostate and prostate cancer cell lines
}

\author{
MARTA SZYSZKA, MARIANNA TYCZEWSKA, PAULINA MILECKA, KAROL JOPEK, \\ PIOTR CELICHOWSKI, LUDWIK K. MALENDOWICZ and MARCIN RUCINSKI
}

Department of Histology and Embryology, Poznan University of Medical Sciences, 60-781 Poznan, Poland

Received June 5, 2017; Accepted October 12, 2017

DOI: $10.3892 /$ or.2017.6066

\begin{abstract}
Results of studies on the expression of leptin and its receptors in the human prostate gland and human prostate cell lines are contradictory. Regarding this, we carefully reinvestigated this issue using human normal prostate (PrEC, PrSC, PrSMC) and prostate cancer (DU145, LNCaP, PC3) cell lines. Expression of leptin receptor isoforms was assessed by qPCR while the effects of leptin on cell proliferative activity was determined by real-time cell analyzer (RTCA). Expression of the leptin receptor variant 1 was not detected in $\mathrm{LNCaP}$ and PrSMC cell lines, but it was found in the remaining cell lines. In contrast, in all examined cell lines, isoforms 1-3 and 2 and 4 of the leptin receptor were found. The expression of isoforms 3 and 6 of the leptin receptor was observed in PC3, PrEC, PrSMC and PrSC cell lines, but not in LNCaP and DU145 cells. Expression of the leptin receptor isoforms 4-6 and 5 was not demonstrated in any of the tested cell lines. We also studied the effects of leptin on the expression of its receptor isoforms in all tested cell lines. At a wide range of concentrations, leptin did not change the expression of leptin receptor variant 1 in the DU145, PrEC and PC3 cell lines. In contrast, in the PrSC cell line, leptin significantly increased the expression of this gene. In all prostate cell lines tested, leptin did not alter the expression levels of variants 1-3 of the leptin receptor isoforms. Leptin did not alter the expression of isoforms 2 and 4 of the leptin receptor in the PC3 and LNCaP cell lines. In the DU145 and PrEC cell lines, leptin inhibited expression of these receptor isoforms while an opposite effect was noted in the PrSC cells. Leptin did not affect the expression level of variants 3 and 6 of its receptor in the PrEC and PC 3 cell lines. However, in PrSMC cells, leptin inhibited the expression of variants 3 and 6 of its receptor, while in the PrSC cell line
\end{abstract}

Correspondence to: Professor Ludwik K. Malendowicz, Department of Histology and Embryology, Poznan University of Medical Sciences, 6 Swiecicki Steet, 60-781 Poznan, Poland

E-mail:1km@amp.edu.pl

Key words: leptin, leptin receptors, human prostate cancer, PrEC, PrSC, PrSMC, DU145, LNCaP, PC3, RT-PCR, proliferation this cytokine significantly increased their expression levels. As assessed by RTCA, leptin stimulated the proliferative activity of DU145 cells, but inhibited this activity in LNCaP cells. At all concentrations tested, leptin did not change the proliferation rate of the PC $3, \mathrm{PrEC}$ and PrSMC cells. In contrast, leptin notably stimulated the proliferative activity of the PrSC (prostate stromal cell) cell line. Thus, our study demonstrated that in all tested human normal prostate and prostate cancer cell lines, transcription variants 4,5 and 6 of the leptin receptor were not expressed. Leptin receptor transcription variants 1 , 2 and 3 showed differential expression, which was present in the PC3, PrEC and PrSC cell lines. Our data also suggest that the stimulatory effects of leptin on proliferative activity of the studied cell lines require the expression of leptin receptor variant 1 in the affected cells.

\section{Introduction}

Obesity is a potential risk factor for the development of various types of cancer. In this regard, the results of a population study suggest that obesity also increases the risk of prostate cancer (PC) development, in particular its aggressive forms (1-8). Both overweight and obesity are closely related to the prevalence of the metabolic syndrome $(9,10)$. In the context of obesity, special attention is paid now to the role of biologically active peptides involved in the regulation of energy homeostasis. Of these, the most important are leptin and ghrelin $(11,12)$. These peptides originate from adipose tissue or the stomach, respectively and both regulate energy homeostasis, mainly at the level of the hypothalamus. Both peptides are involved in the regulation of body weight, food intake and energy homeostasis and their mutual interaction is known as a 'ghrelin-leptin tango' (13-16). It is worth emphasizing that in the regulation of energy homeostasis, leptin exerts a long-term effect, while ghrelin is rather a fast-acting signal. In light of the above mentioned 'tango dancers', we aimed to investigate leptin, whose blood levels are elevated in obese individuals. In addition, in many tissues, this cytokine exerts a significant mitogenic effect, inter alia, in the prostate.

Studies on leptin-deficient mouse led the group of Friedman to the discovery of a leptin (17). They also identified the leptin gene $(O B)$ which encodes the synthesis of proleptin 
consisting of 166 amino acids. The mature form of circulating leptin is composed of 146-amino acid residues $(18,19)$. The leptin gene is almost exclusively expressed in adipose tissue. This hormone exerts biological effects through the leptin receptor (OB-R) (20). As described by them, the receptor is the so-called long leptin receptor, which exerts full biological activity. Subsequently Cioffi et al (21) identified three variants of the short leptin receptor, which they called huB219.1, huB219.2 and huB219.3.

In the early days of research, leptin receptor isoforms were determined by letters, respectively $\mathrm{Ob}-\mathrm{Ra}, \mathrm{Ob}-\mathrm{Rb}, \mathrm{Ob}-\mathrm{Rc}$, $\mathrm{Ob}-\mathrm{Rd}, \mathrm{Ob}-\mathrm{Re}$ and $\mathrm{Ob}-\mathrm{Rf}$ (reviewed in ref. 22). This nomenclature is still used in relation to the leptin receptor in rats, in the prostate of which such isoforms are present (23). However, with regard to the human leptin receptor isoforms, this nomenclature has totally changed. Current data indicate that there are six isoforms of the human leptin receptor (Table I). It should be emphasized that the transcript corresponding to the soluble leptin isoform was not demonstrated in humans $(24,25)$. Therefore, it has been suggested that in humans this receptor originates from proteolytic cleavage of ectodomains of the remaining receptor isoforms. Isoforms of the leptin receptor are ubiquitously expressed and show a tissue-specific distribution $(21,26,27)$.

Expression of leptin receptor isoforms is also found in the human prostate and in human normal prostate and cancer prostate cell lines. As early as 1996, Cioffi et al, by means of RT-PCR, demonstrated high expression of the B219/obr gene in the human prostate (21). Subsequently, by means of immunohistochemistry, leptin receptors were found in epithelial cells in both normal and malignant prostate glands (28). In benign prostatic hyperplasia, expression of OB-R was found in 2 out of 5 studied cases; HuB219.1 was present in all cases and $\mathrm{HuB} 219.2$ and HuB219.3 isoforms were noted in 3 and 4 cases, respectively (29). Leptin receptor isoforms are also expressed in prostate cancer cell lines. Two functional receptor isoforms (huOB-R and huB219.3) were found in DU145, PC-3, and LNCaP-FGC cell lines (30). Furthermore, expression of huOb-Ra and huOb-Rb was reported in DU145 and PC3 cell lines (31). Multiple alignment of the DNA sequences of leptin receptor gene isoforms revealed that in these studies huOB-R and huOb-Rb are the same isoforms (comparison of data from Genebank), while huOb-Ra $=$ huB219.3 = variant 6 . Current leptin receptor gene structure indicates that it might be impossible to design specific primers only for variant 6 ; therefore we suggest that authors determine the total expression of leptin receptor variants 3 and/or 6 .

Experimental data indicate that leptin exerts a multidirectional effect on human prostate cancer cells. Available data suggest that in different human normal prostate and prostate cancer cell lines, leptin may influence cellular differentiation, proliferation, apoptosis, migration, invasion, metastatic potential and release of growth factors. Previous studies have been usually carried out on a small number of cell lines and often provide controversial results. Therefore, the objective of the present study was to investigate the expression of leptin receptor isoforms in human normal prostate and prostate cancer cell lines, to investigate the effect of leptin on the expression level of these receptors and to study the effect of leptin on the proliferation rate of these cells.

\section{Materials and methods}

Cell culture. The human prostate cell lines, prostate epithelial cells (PrEC, cat. no. CC-2555), prostate stromal cells (PrSC, cat. no. CC-2508) and prostate smooth muscle cells (PrSMC, cat. no. CC-2587) were purchased from Lonza (Walkersville, MD, USA). Each cell line was grown under specific conditions, including special medium in accordance with the recommendations of the provider. Prostate epithelial PrEC cells were grown using the Prostate Epithelial Cell Medium BulletKit ${ }^{\mathrm{TM}}$ (PrEGM) containing bovine pituitary extract (BPE), hydrocortisone, hEGF, epinephrine, transferrin, insulin, retinoic acid, triiodothyronine, and GA-1000 (gentamycin) (Lonza). Prostate stromal PrSC cells were grown using the Stromal Cell Medium BulletKit (SCGM) containing growth supplements [hFGF-B, insulin, fetal bovine serum (FBS), GA-1000 (Lonza)]. Prostate smooth muscle PrSMC cells were grown using the Smooth Muscle Cell Medium BulletKit (SmGM-2) containing growth supplements [hEGF, insulin, hFGF-B, FBS and GA-1000 (Lonza)]. Prostate carcinoma cell lines, LNCaP [LNCaP clone FGC (ATCC ${ }^{\circledR}$ CRL-1740D ${ }^{\mathrm{TM}}$ )], DU145 (ATCC HTB-81 ${ }^{\mathrm{TM}}$ ) and PC3 (ATCC CRL-1435 ${ }^{\mathrm{TM}}$ ) were purchased from ATCC (American Type Culture Collection, Manassas, VA, USA). LNCaP and DU145 cells were grown in RPMI1640 medium $(1 \mathrm{X})$ + GlutaMAX + HEPES (Gibco Life Technologies, Carlsbad, CA, USA). PC3 cells were grown in F-12K medium commercially available from ATCC. All cell lines were cultured in Falcon flasks in a humidified incubator at $37^{\circ} \mathrm{C}$ in $5 \% \mathrm{CO}_{2}$. After seeding on the first day, the culture medium was replaced with a new one and then changed every second day. All cell lines were cultured for 3-4 days but LNCaP cells for 7-8 days, and subsequently the cells were transferred into culture wells $(32,33)$.

Leptin receptor isoform expression. To study the effects of leptin on leptin receptor isoform expression, cells were transferred into 6-well plates (Nunc). First, the cells were cultured for $24 \mathrm{~h}$ in specific medium as mentioned above. Subsequently cells were incubated for another $96 \mathrm{~h}$ in starved medium - without FBS, but with HEPES, glucose and antibiotics (LNCaP, DU145, PC3 cell lines). Normal prostate cell lines, PrEC, PrSMC, PrSC, were incubated in a medium with special FBS, charcoal stripped (Gibco Life Technologies). From day 3 of culture, new medium with leptin at concentrations $1 \times 10^{-6}$, $1 \times 10^{-8}$ and $1 \times 10^{-10} \mathrm{M}$ was added, and the cells were incubated for at least 2 days (without changing medium). These concentrations are within the range of leptin concentrations in human blood. The serum leptin concentration in healthy human blood is $6.6-20 \mathrm{ng} / \mathrm{ml}$, while in obese individuals it is $30-80 \mathrm{ng} / \mathrm{ml}$. The concentration of $1 \times 10^{-10} \mathrm{M}$ corresponds to a concentration of $1.6 \mathrm{ng} / \mathrm{ml}$, and $1 \times 10^{-8} \mathrm{M}$ to a concentration of $160 \mathrm{ng} / \mathrm{ml}$. Thus, the leptin concentrations used in the incubation medium (excluding $10^{-6} \mathrm{M}$ concentration) are similar to serum leptin levels in healthy and obese subjects.

RNA isolation. At the end of culture, the cells were washed two times using PBS, and then the total RNA was extracted using TRI Reagent (Sigma-Aldrich, Poznan, Poland). Medium from each well was collected into tubes and frozen for ELISA research. Total RNA was purified on columns (NucleoSpin 
Table I. Human leptin receptor isoforms - actual nomenclature and original terminology (Genebank, accession January 2017).

Actual terminology

\begin{tabular}{|c|c|c|c|c|c|}
\hline LEPR var 1 & LEPR var 2 & LEPR var 3 & LEPR var 4 & LEPR var 5 & LEPR var 6 \\
\hline Homo sapiens & Homo sapiens & Homo sapiens & Homo sapiens & Homo sapiens & Homo sapiens \\
\hline $\begin{array}{l}\text { leptin receptor } \\
\text { (LEPR), } \\
\text { transcript } \\
\text { variant } 1 \text {, } \\
\text { mRNA. }\end{array}$ & $\begin{array}{l}\text { leptin receptor } \\
\text { (LEPR), } \\
\text { transcript } \\
\text { variant } 2 \text {, } \\
\text { mRNA. }\end{array}$ & $\begin{array}{l}\text { leptin receptor } \\
\text { (LEPR), } \\
\text { transcript } \\
\text { variant 3, } \\
\text { mRNA. }\end{array}$ & $\begin{array}{l}\text { leptin receptor } \\
\text { (LEPR), } \\
\text { transcript } \\
\text { variant 4, } \\
\text { mRNA. }\end{array}$ & $\begin{array}{l}\text { leptin receptor } \\
\text { (LEPR), } \\
\text { transcript } \\
\text { variant 5, } \\
\text { mRNA. }\end{array}$ & $\begin{array}{l}\text { leptin receptor } \\
\text { (LEPR), } \\
\text { transcript } \\
\text { variant 6, } \\
\text { mRNA. }\end{array}$ \\
\hline NM_002303.5 & NM_001003680.3 & NM_001003679.3 & NM_001198687.1 & NM_001198688.1 & NM_001198689 \\
\hline 4,161 bp mRNA & 3,079 bp mRNA & 5,142 bp mRNA & 3,044 bp mRNA & 2,935 bp mRNA & 5,107 bp mRNA \\
\hline 6-Oct-2016 & 6-Oct-2016 & 6-Oct-2016 & 6-Oct-2016 & 7-Oct-2016 & 7-Oct-2016 \\
\hline
\end{tabular}

Original terminology

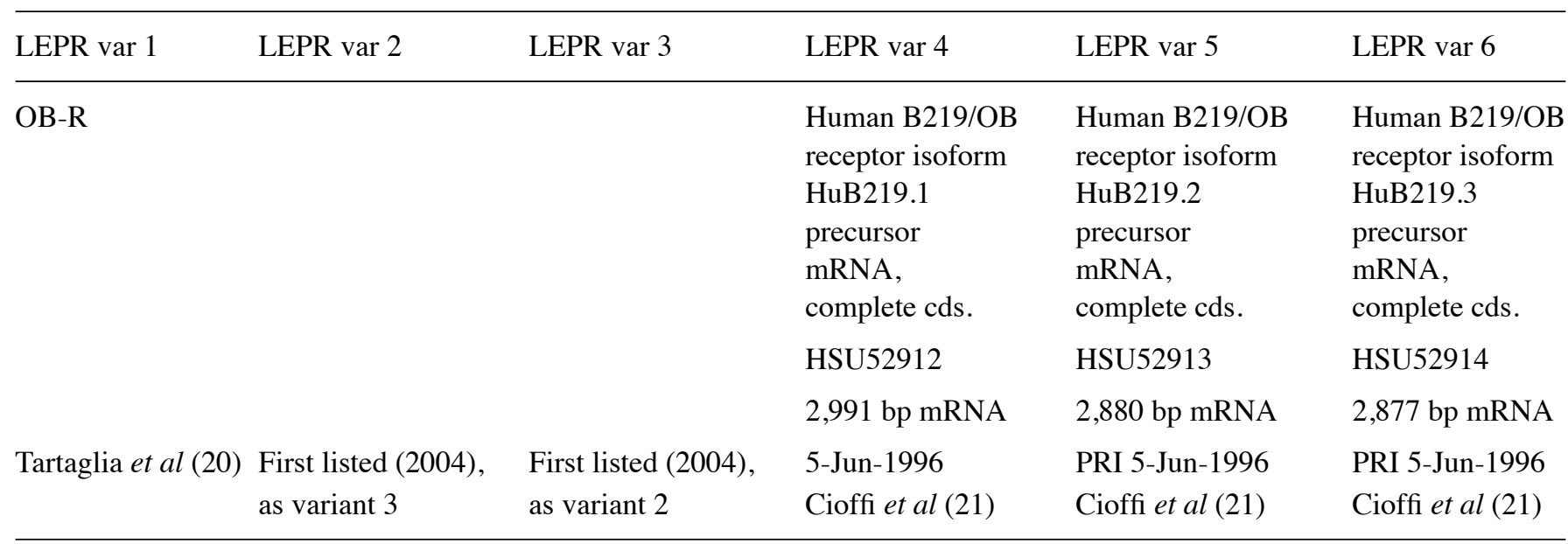

Total RNA Isolation, Qiagen GmbH, Hilden, Germany) (33-36). The amount of total RNA was determined by optical density at $260 \mathrm{~nm}$ and its purity was estimated by a 260/280 $\mathrm{nm}$ absorption ratio (higher than 1.8) (NanoDrop spectrophotometer, Thermo Fisher Scientific, Waltham, MA, USA).

Reverse transcription. Reverse transcription was performed using reverse transcriptase from the Transcriptor First Strand cDNA Synthesis kit (Roche Diagnostics Corp., Indianapolis, IN, USA) with Oligo(dT) as primers at a temperature of $55^{\circ} \mathrm{C}$ for $40 \mathrm{~min}$ (Thermocycler UNO II, Biometra $\mathrm{GmbH}$, Göttingen, Germany). Total RNA $(1 \mu \mathrm{g})$ was used for a single $\mathrm{RT}$ reaction. The RTs were carried out in standard final volumes $(20 \mu \mathrm{l})$. After RT, each cDNA containing sample was diluted with $100 \mu \mathrm{l}$ of RNase-free water.

$q P C R$. Primers were designed by Primer 3 software (Whitehead Institute for Biomedical Research, Cambridge, MA, USA) and purchased from the Laboratory of DNA Sequencing and Oligonucleotide Synthesis, Institute of Biochemistry and Biophysics, Polish Academy of Sciences, Warsaw (Fig. 1, Table II). qPCR was performed by means of the Lightcycler 2.0 instrument (Roche Diagnostics Corp., 4.05 software version). Using the above mentioned primers, SYBR
Green detection system was applied. Every $20 \mu 1$ of reaction mixtures contained $2 \mu \mathrm{l}$ template cDNA (standard or control), $0.5 \mu \mathrm{M}$ of each specific primer, and a previously determined optimum $\mathrm{MgCl}_{2}$ concentration (3.5 $\mu \mathrm{M}$ for each reaction). According to the Roche LightCycler FastStart DNA Master SYBR-Green 1 kit procedure for qPCR, 1-5 $\mu \mathrm{l}$ of the RT reaction product (cDNA) can be used in $20 \mu \mathrm{l}$ or $50 \mu \mathrm{l}$ final reaction volume. LightCyclerFastStart DNA Master SYBR-Green I mix program (Roche Diagnostics Corp.) was used. The real-time PCR program included $10 \mathrm{~min}$ of a denaturation step to activate the Taq DNA polymerase, followed by a three-step amplification program: denaturation at $95^{\circ} \mathrm{C}$ for $10 \mathrm{sec}$, annealing at $56^{\circ} \mathrm{C}$ for $5 \mathrm{sec}$, and extension at $72^{\circ} \mathrm{C}$ for $5 \mathrm{sec}$. Assays were run for a maximal 45 cycles. Specificity of the reaction products was checked by the determination of melting points $\left(0.1^{\circ} \mathrm{C} / \mathrm{sec}\right.$ transition rate). HPRT was used as a standard for controlling RT-PCR reaction quality as well as the reference gene in prostate cell lines. The primers used exhibited a positive reaction in human organs, as demonstrated in our previous study (37).

Proliferation assay (in vitro culture using a real-time cell analyzer - RTCA). The study used an electrical impedancebased technique, the real-time cell analyzer (RTCA, Roche Applied Science, Penzberg, Germany). The system consists of 


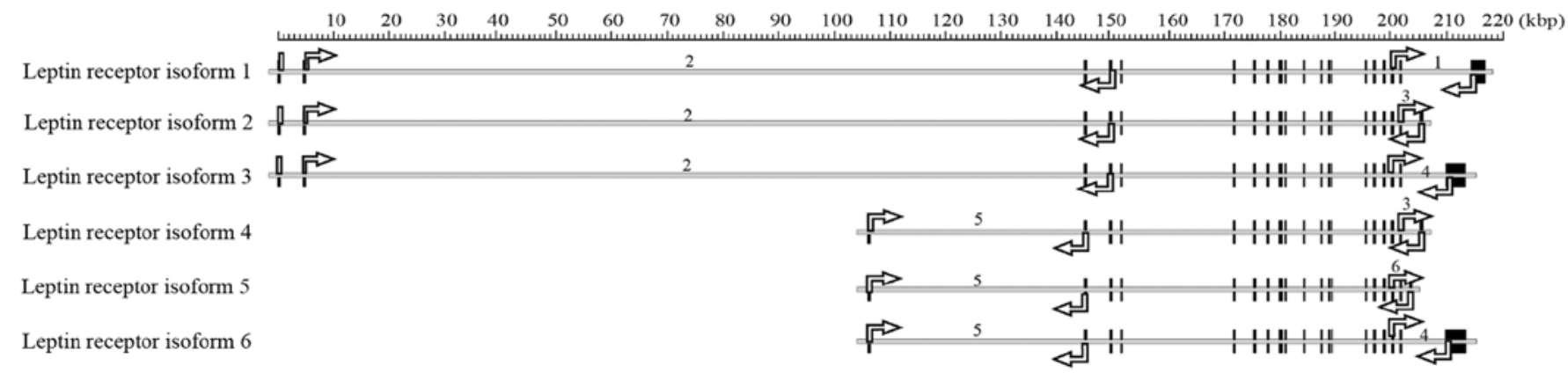

Figure 1. Structure of the human leptin receptor gene. It presents six known transcription variants, in which individual exons are shown as vertical lines. The width of the vertical line corresponds to the length of an individual exon. Arrows show primer binding sites for all distinguishable transcript variants of the leptin receptor gene. For each pair of primers used, appropriate numbers were assigned that correspond to the numbering in the table presenting data on the primers used (Table II).

Table II. PCR analyses of leptin receptor isoforms.

[Position on Fig. 1],

Genebank accession number of transcript variant Primer Primer sequence (5'-3')

\section{[1] NM_002303.5} transcript variant 1

[2] NM_002303.5, NM_001003680.3, NM_001003679.3 transcript variant 1-3

[3] NM_001003680.3, NM_001198687.1

$$
\text { GCCAGTAATTATTTCCTCTTCC }
$$
CCCTGGGTACTTGAGATTAG

transcript variant 2,4

[4] NM_001003679.3, NM_001198689.1

transcript variant 3,6

[5] NM_001198687.1, NM_001198688.1,

NM_001198689.1

transcript variant 4-6

[6] NM_001198688.1 transcript variant 5

NM_000194.2

Homo sapiens hypoxanthine phosphoribosyltransferase 1

TATGTAATTGTGCCAGTAA ACATTGGGTTCATCTGTAGTG

A

S

A

CTGCCTTCGGTCGAGTTGGA

S TCCCCATTGAGAAGTACCAGT

S GCCATCACATTGTAGCCCTC

A ACTTTTATGTCCCCTGTTGACT

$\begin{array}{ll}\text { S } & \text { CAGAGTGATGCAGGTTTATATG } \\ \text { A } & \text { CTGATGCTGTATGCTTGATAA } \\ \text { S } & \text { CGGGCGTTAAAGCTCTCGT } \\ \text { A } & \text { GCTCACTCCGAAAGCAACAGT }\end{array}$
CAGCAGGCAAAAGGAAGTAGTCA

2723-2744

2920-2901

(in relation to NM_001003680.3)

2712-2730

2911-2891

(in relation to NM_001003679.3)

98-117

304-282

2555-2575

300

2854-2834

343-362 size

(bp)

Position on Fig. 1 in [brackets]; Genebank accession number; no. of transcript variant; oligonucleotide sequences for sense (S) and antisense (A) primers, their position and product size are shown. Homo sapiens hypoxanthine phosphoribosyltransferase 1 (HPRT) was used as the reference gene.

an RTCA analyzer, an RTCA SP station and RTCA software. As described by the manufacturer, the main read-out of the RTPA is a dimensionless parameter 'Cell Index'. This index is derived as a relative change in measured electrical impedance to represent cell status. From RTCA software, the slope values of the proliferation rates were extracted at times of exponential growth of the control groups (no leptin addition), as indicated in the appropriate figures. 
Table III. Analysis of expression of the leptin receptor isoforms in the tested cell lines of the human prostate.

Neoplastic prostate cells

\begin{tabular}{|c|c|c|c|c|c|c|c|c|c|}
\hline \multirow{2}{*}{$\frac{\text { Cell line (identified transcript variant) }}{\text { Leptin concentration }(\mathrm{M}) \rightarrow}$} & \multicolumn{3}{|c|}{$\mathrm{LNCaP}(\operatorname{var} 2)$} & \multicolumn{3}{|c|}{ DU145 (var 1,2) } & \multicolumn{3}{|c|}{ PC3 (var 1, 2, 3) } \\
\hline & $10^{-6}$ & $10^{-8}$ & $10^{-10}$ & $10^{-6}$ & $10^{-8}$ & $10^{-10}$ & $10^{-6}$ & $10^{-8}$ & $10^{-10}$ \\
\hline \multicolumn{10}{|l|}{ Leptin receptor isoform expression $\downarrow$} \\
\hline var 1-3 & $=$ & $=$ & $=$ & $=$ & $=$ & $=$ & $=$ & $=$ & $=$ \\
\hline $\operatorname{var} 2,4$ & $=$ & $=$ & $=$ & $=$ & $\boldsymbol{\nabla}$ & $\boldsymbol{\nabla}$ & $=$ & $=$ & $=$ \\
\hline $\operatorname{var} 3,6$ & - & - & - & - & - & - & $=$ & $=$ & $=$ \\
\hline Proliferation rate & $\boldsymbol{\nabla}$ & $=$ & $=$ & $\Delta$ & $=$ & $=$ & $=$ & $=$ & $=$ \\
\hline
\end{tabular}

Normal prostate cells

\begin{tabular}{|c|c|c|c|c|c|c|c|c|c|}
\hline \multirow{2}{*}{$\frac{\text { Cell line (identified transcript variant) }}{\text { Leptin concentration }(\mathrm{M}) \rightarrow}$} & \multicolumn{3}{|c|}{$\operatorname{PrEC}(\operatorname{var} 1,2,3)$} & \multicolumn{3}{|c|}{$\operatorname{PrSMC}(\operatorname{var} 2,3)$} & \multicolumn{3}{|c|}{$\operatorname{PrSC}(\operatorname{var} 1,2,3)$} \\
\hline & $10^{-6}$ & $10^{-8}$ & $10^{-10}$ & $10^{-6}$ & $10^{-8}$ & $10^{-10}$ & $10^{-6}$ & $10^{-8}$ & $10^{-10}$ \\
\hline $\begin{array}{l}\text { Leptin receptor isoform expression } \downarrow \\
\text { var } 1\end{array}$ & $=$ & $=$ & $=$ & - & - & - & $=$ & $=$ & $\Delta$ \\
\hline var $1-3$ & $=$ & $=$ & $=$ & $=$ & $=$ & $=$ & $=$ & $=$ & $=$ \\
\hline $\operatorname{var} 2,4$ & $=$ & $\boldsymbol{\nabla}$ & $\boldsymbol{\nabla}$ & $=$ & $=$ & $=$ & $=$ & $=$ & $\Delta$ \\
\hline $\operatorname{var} 3,6$ & $=$ & $=$ & $=$ & $=$ & $\boldsymbol{\nabla}$ & $=$ & $=$ & $=$ & $\Delta$ \\
\hline Proliferation rate & $=$ & $=$ & $=$ & $=$ & $=$ & $=$ & $=$ & $\Delta$ & $\Delta$ \\
\hline
\end{tabular}

'-' no expression; '=' not changed significantly; ' $\mathbf{\wedge}$ ' significantly upregulated; ' $\boldsymbol{\nabla}$ ' significantly downregulated. Next to the name of the cell line in brackets are given the identified variants (isoforms) of leptin receptor.

Six human normal prostate and prostate cancer cell lines were cultured in E-Plate 48 of RTCA for at least $112 \mathrm{~h}$. After the first $24 \mathrm{~h}$, cells were cultured in starved medium (medium without growth factors) or in special FBS, charcoal stripped medium (see above). At $48 \mathrm{~h}$ of culture, leptin at concentrations $1 \times 10^{-6}, 1 \times 10^{-8}$ and $1 \times 10^{-10} \mathrm{M}$ was added and cells were incubated for at least $48 \mathrm{~h}$. Cell index was recorded every $15 \mathrm{~min}$ and an exemplary chart plot is shown in Fig. 6. Subsequently this cell index was normalized (normalized cell index). To improve the readability of figures, on the normalized diagrams, points are marked every $45 \mathrm{~min}$. From RTCA software, the slope values of the proliferation rates of cultured human normal prostate and prostate cancer cell lines were extracted from each well. Each experiment was repeated at least three times.

Statistical analysis. Where applicable, data presented are means \pm SEM. Statistical analysis of the data was performed using one-way analysis of variance (ANOVA) followed by Tukey's HSD test. Calculation was made by means of $\mathrm{R}$ environment with multcomp library. Results were considered as statistically significant when $P$ values from ANOVA were $<0.05$. In such cases, post-hoc Tukey's HSD test was performed. In this case, the threshold of statistical significance was set again to 0.05 . In the figures, results of the Tukey's HSD test are marked by letters. Groups sharing the same letter are not significantly different according to Tukey's HSD test.

\section{Results}

Expression of leptin receptor isoforms. As summarized in Table III, expression of the leptin receptor variant 1 was not detected in LNCaP and PrSMC cell lines, but it was found in the remaining cell lines. On the other hand, in all examined cell lines, isoforms $1-3$, and 2 and 4 of the leptin receptor were found. The expression of isoforms 3 and 6 of the leptin receptor was observed in PC $3, \operatorname{PrEC}, \operatorname{PrSMC}$ and PrSC cell lines, but not in LNCaP and DU145 cells. Expression of the leptin receptor isoforms 4-6 and 5 was not demonstrated in any of the tested cell lines. Analysis of the data showed that from the amplification product of variants 2 and 4, the expression of variant 4 may be ruled out. It follows that all tested cell lines expressed variant 2 of the leptin receptor. In turn, in lines PC3, PrEC, PrSMC and PrSC from the amplification product of variant 3 and 6 of the leptin receptor, isoform 6 can be excluded. Therefore, observed expression is caused exclusively by isoform 3 of the leptin receptor. It should be noted that in samples obtained from human adrenal we found expression of all isoforms of the leptin receptor. This proves the correctness of the primers used in the present study.

We also conducted experiments on the effects of leptin on the expression of its receptor isoforms in all tested cell lines. As is apparent from Fig. 2 at a wide range of concentrations, leptin did not change the expression of leptin receptor variant 1 

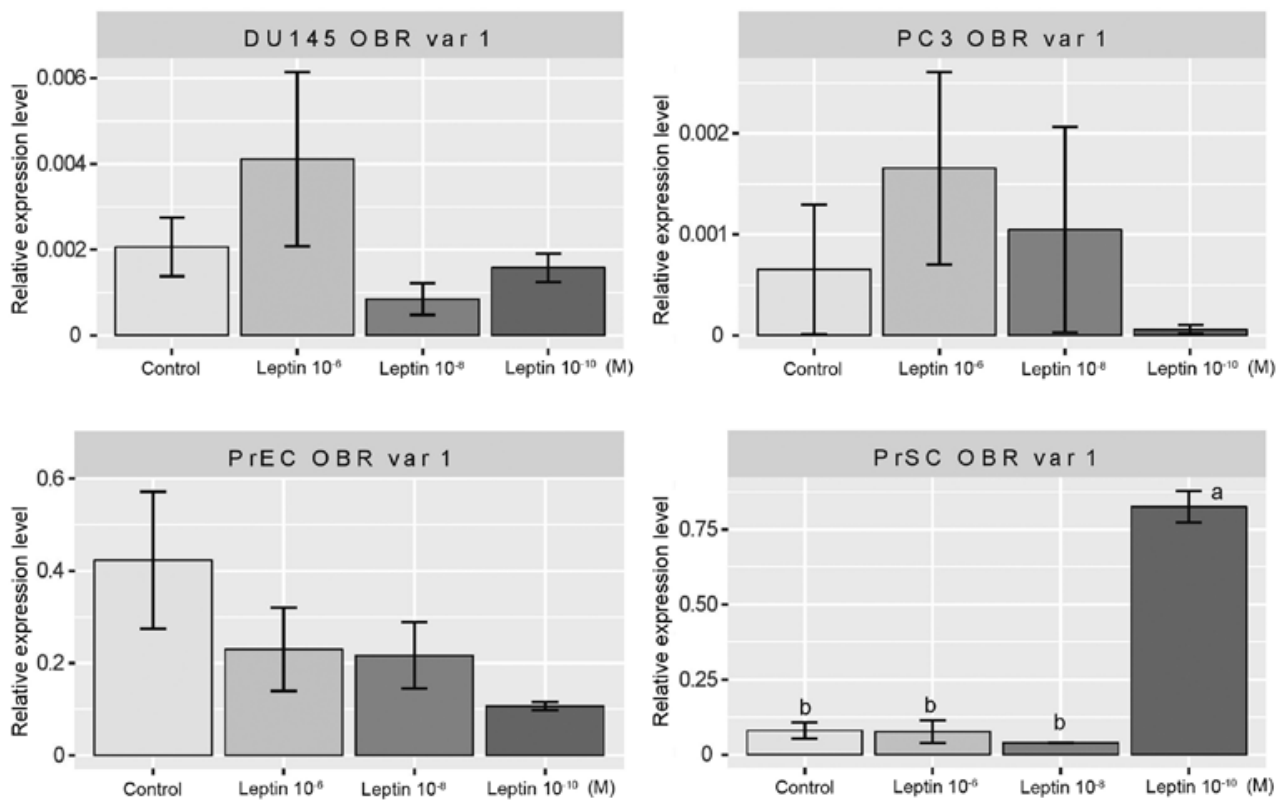

Figure 2. Effects of leptin on expression levels of leptin receptor variant 1 in DU145, PC3, PrEC and PrSC human prostate cell lines. Cells were incubated in starved specific medium (as described in Materials and methods) for at least for 2 days. Bars presenting means $\pm \mathrm{SE}$ are shown. In each group, $\mathrm{n}=4$. There are no statistically significant differences between group means as determined by one-way ANOVA for DU145 ( $\mathrm{P}=0.964), \mathrm{PC} 3(\mathrm{P}=0.62)$ and $\mathrm{PrEC}$ ( $\mathrm{P}=0.201)$ cell lines. For PrSC cells $\mathrm{P}=0.0136$. Groups sharing the same letter are not significantly different according to Tukey's HSD test.
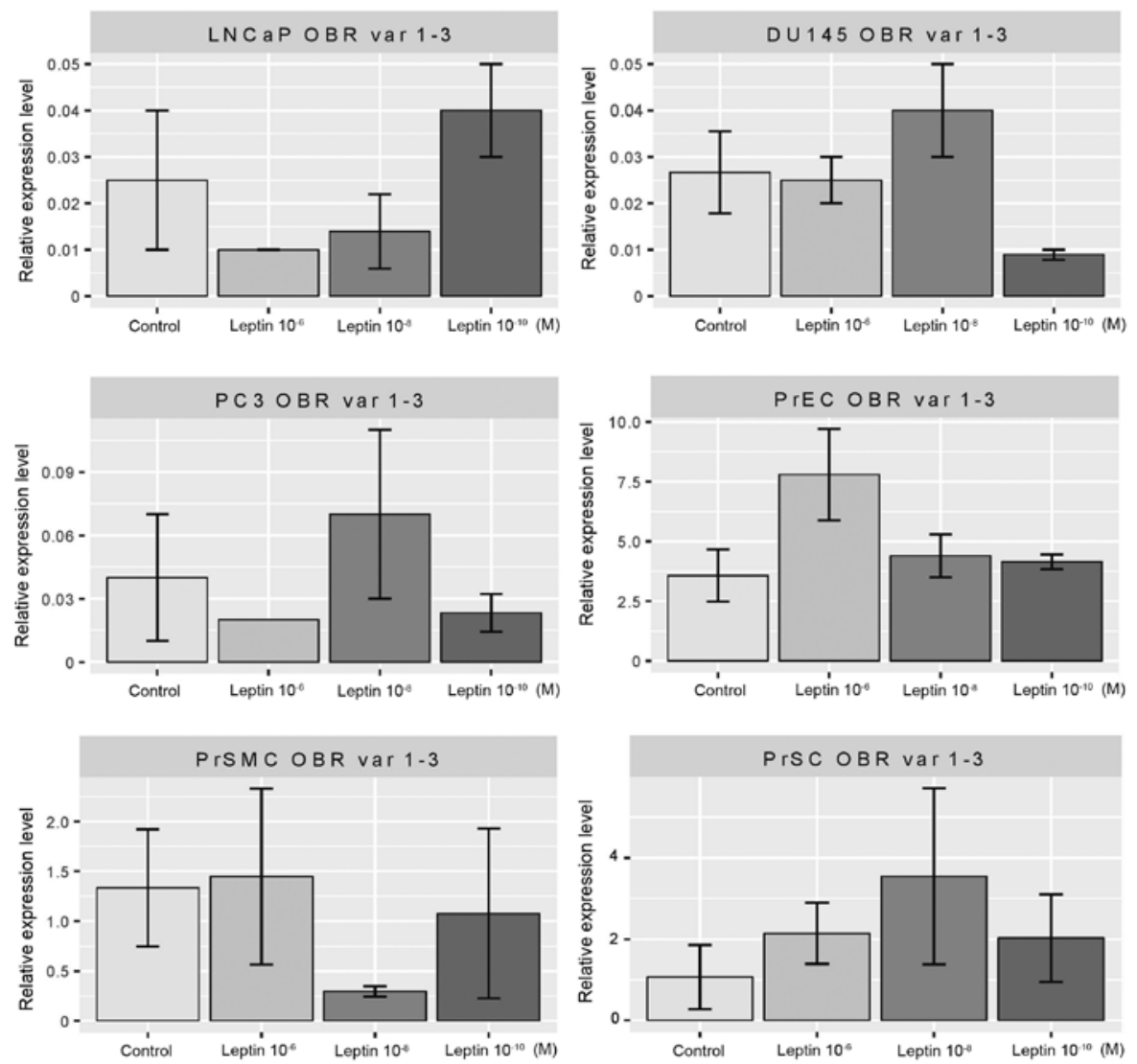

Figure 3. Effects of leptin on expression levels of leptin receptor variants 1-3 in LNCaP; DU145, PC3, PrEC, PrSMC and PrSC human prostate cell lines. Cells were incubated in starved specific medium (as described in Materials and methods) for at least 2 days. Bars presenting means \pm SE are shown. In each group, $\mathrm{n}=4$. There were no statistically significant differences between group means as determined by one-way ANOVA for all cell lines: $\mathrm{LNCaP}(\mathrm{P}=0.212)$, DU145 $(\mathrm{P}=0.506), \mathrm{PC} 3(\mathrm{P}=0.582), \operatorname{PrEC}(\mathrm{P}=0,13)$, PrSMC $(\mathrm{P}=0.383)$ and $\operatorname{PrSC}(\mathrm{P}=0.637)$.

in DU145, PrEC and PC3 cell lines. In contrast, in the PrSC cell line, leptin at $10^{-10} \mathrm{M}$ significantly increased the expres- sion of the gene of interest, while higher concentrations of the cytokine did not exert such an effect. 

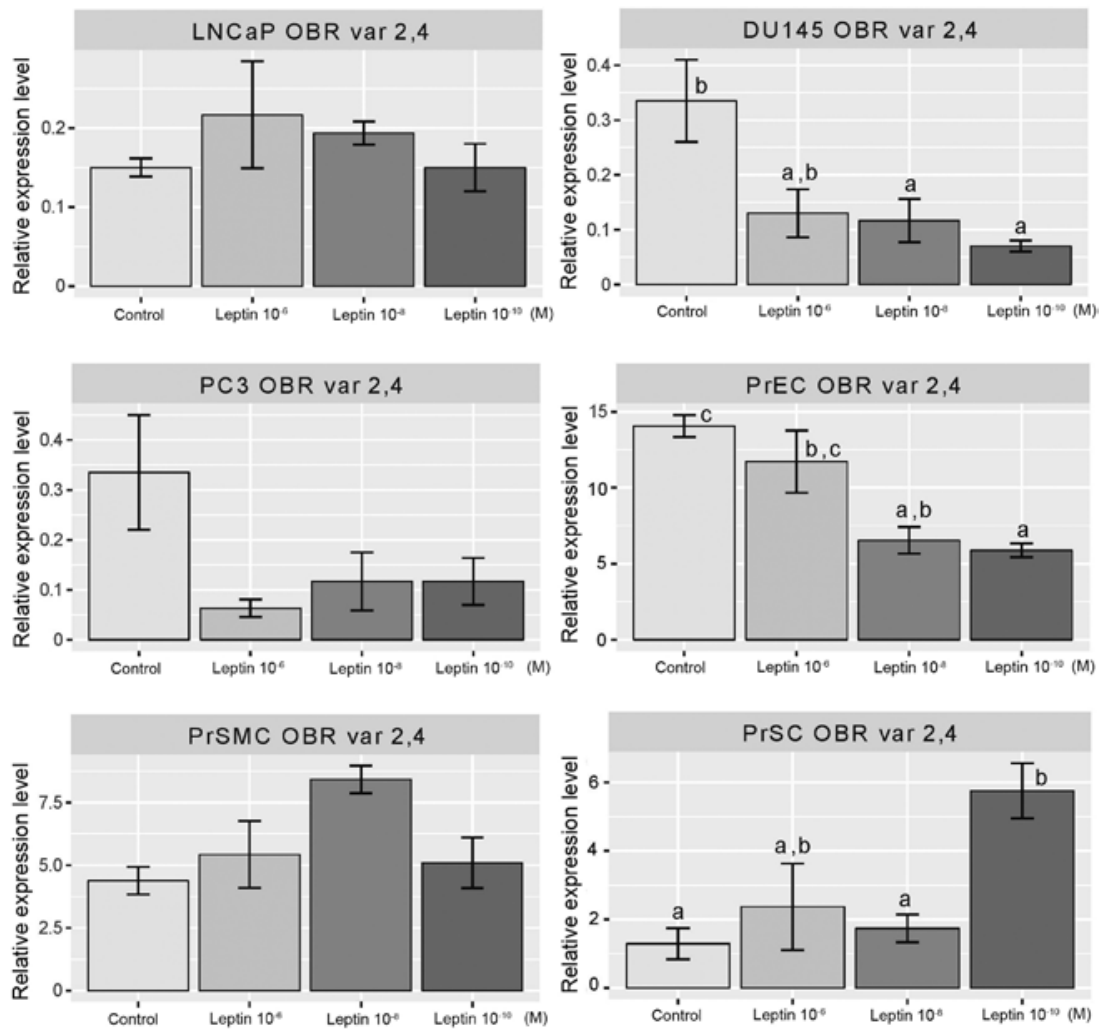

Figure 4. Effects of leptin on expression levels of leptin receptor variants 2 and 4 in LNCaP, DU145, PC3, PrEC, PrSMC and PrSC human prostate cell lines. Cells were incubated in starved specific medium (as described in Materials and methods) for at least 2 days. Bars presenting means \pm SE are shown. In each group, $n=4$. There were no statistically significant differences between group means as determined by one-way ANOVA for $\mathrm{LNCaP}(\mathrm{P}=0.594), \mathrm{PC} 3(\mathrm{P}=0.0712)$ and PrSMC $(\mathrm{P}=0.0529)$ cell lines. In the remaining cell lines, groups sharing the same letter were not significantly different according to Tukey's HSD test.
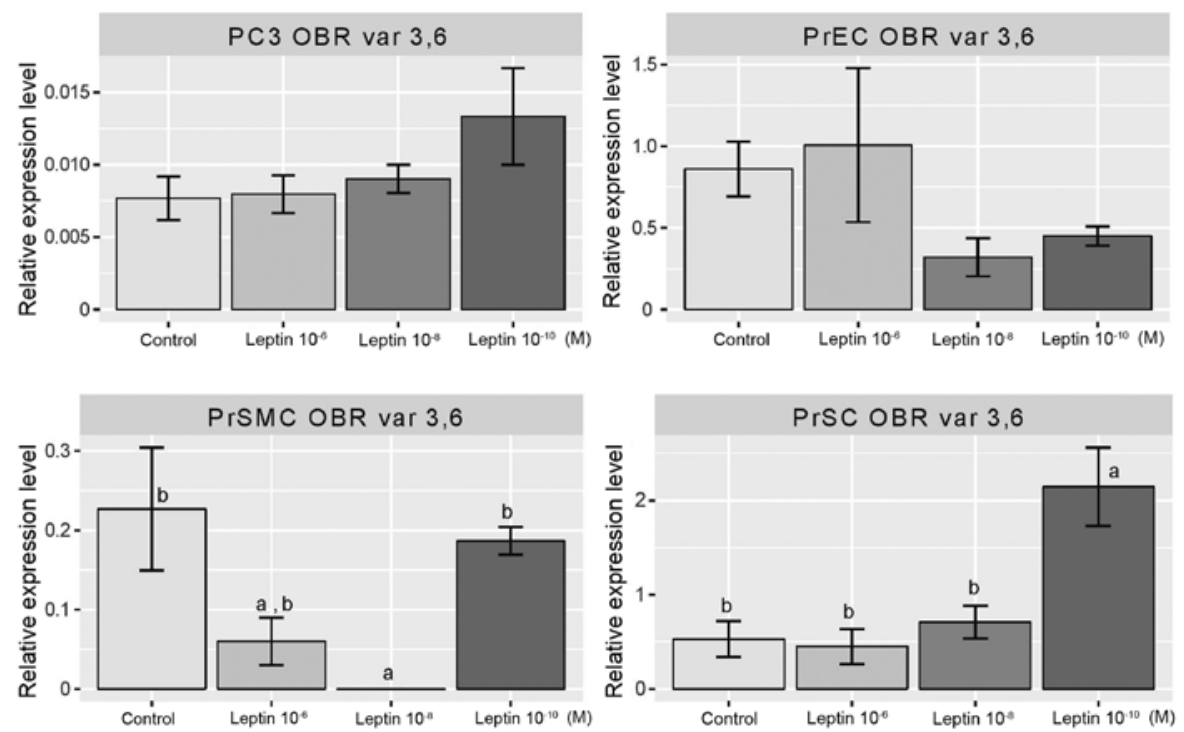

Figure 5. Effects of leptin on expression levels of leptin receptor variants 3 and 6 in PC3, PrEC, PrSMC and PrSC human prostate cell lines. Cells were incubated in starved specific medium (as described in Materials and methods) for at least 2 days. Bars presenting means $\pm \mathrm{SE}$ are shown. In each group, $\mathrm{n}=4$. There were no statistically significant differences between group means as determined by one-way ANOVA for $\mathrm{PC} 3(\mathrm{P}=0.284)$ and $\mathrm{PrEC}(\mathrm{P}=0.266)$ cell lines In the remaining cell lines, groups sharing the same letter were not significantly different according to Tukey's HSD test.

In the prostate cell lines tested, LNCaP, PC3, DU145, PrEC, PrSMC and PrSC, leptin did not change the expression levels of variants 1-3 of the leptin receptor isoforms (Fig. 3). Concerning variants 2 and 4 of the leptin receptor isoforms, the applied cytokine did not alter their expression in the
LNCaP, PC3 and PrSMC cell lines (Fig. 4). In the DU145 (at $10^{-8}$ and $10^{-10} \mathrm{M}$ ) and PrEC cells (at concentrations of $10^{-8}$ and $10^{-10} \mathrm{M}$ ) leptin inhibited expression of the receptor isoforms tested. In contrast, in the PrSC cells (at $10^{-10} \mathrm{M}$ ), this cytokine substantially enhanced expression of the studied genes. 


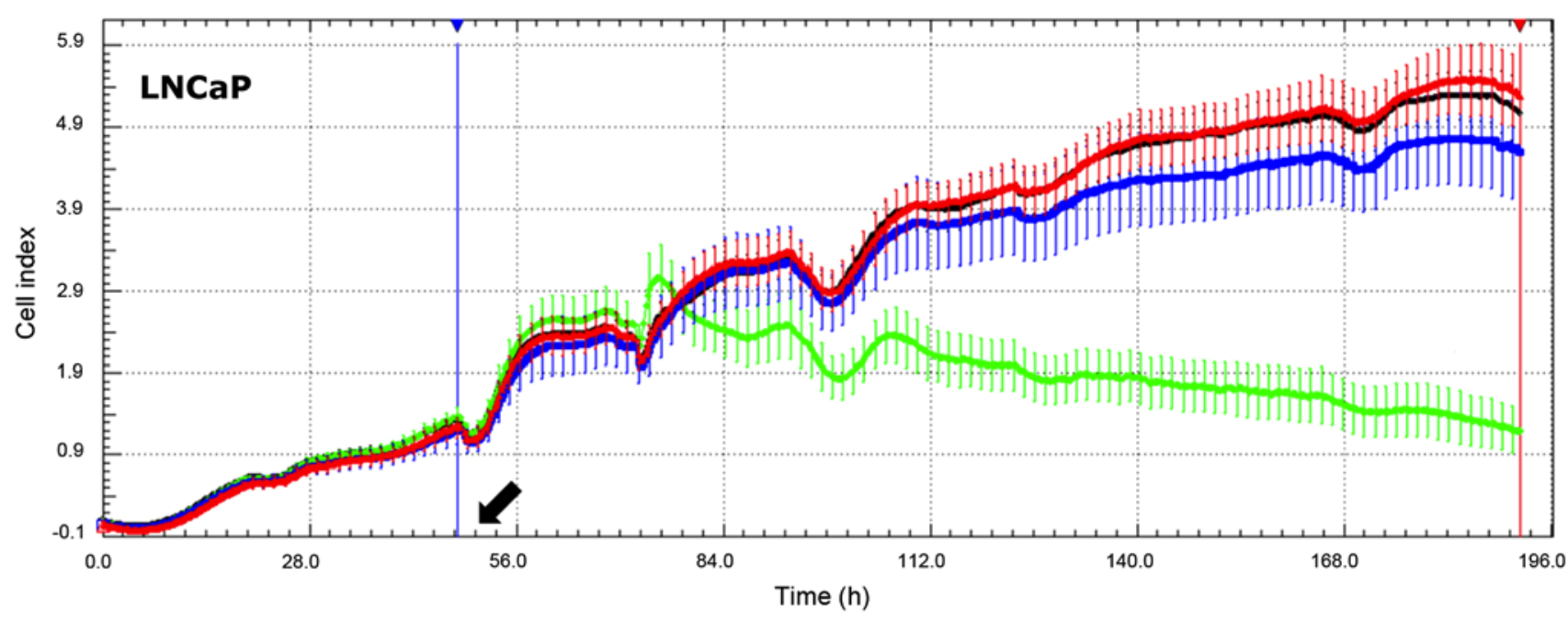

Figure 6. RTCA (real-time cell analyzer) delivered cell index of LNCaP cells cultured for $196 \mathrm{~h}$ in the presence of various leptin concentrations. Cell index was recorded every $15 \mathrm{~min}$. Point of leptin addition is shown by a black arrow. Black line, control (no leptin addition); green line, leptin 1x10-6 $\mathrm{M}$; blue line, leptin $1 \times 10^{-8} \mathrm{M}$; red line, leptin $1 \times 10^{-10} \mathrm{M}$.

Leptin did not affect the expression level of variants 3 and 6 of its receptor in the PC3 and PrEC cell lines (Fig. 5). However, in PrSMC cells leptin at concentrations of $10^{-6}$ and $10^{-8} \mathrm{M}$ inhibited the expression of the genes of interest. In contrast, in the PrSC cell line, this cytokine at $10^{-10} \mathrm{M}$ significantly increased the level of expression of the receptor isoforms tested.

Proliferation assay. In this study, we were interested in using the RTCA platform to monitor the effects of leptin on proliferation of human normal prostate and prostate cancer cell lines. As documented in Fig. 7, in the DU145 cell line leptin at a concentration $1 \times 10^{-6} \mathrm{M}$ stimulated the proliferation rate, while lower leptin concentrations were ineffective. In contrast, in the LNCaP cell line, the same leptin concentration exerted an inhibitory effect on proliferative activity, and again lower leptin concentrations did not change the studied parameter. For all leptin concentrations, the proliferation rate of PC 3 cells remained unchanged. Likewise, at all concentrations, leptin did not affect the proliferation of PrEC or PrSMC cell lines. In contrast, leptin at concentrations $1 \times 10^{-8}$ and $1 \times 10^{-10} \mathrm{M}$ notably stimulated proliferative activity of the PrSC (prostate stromal cell) cell line.

\section{Discussion}

In light of the controversial data concerning the influence of leptin on human normal prostate and prostate cancer cell lines, we performed a comprehensive and systematic study on LNCaP, DU145, PC3, PrEC, PrSMC and PrSC cell lines. In the first instance, we examined the expression of leptin receptor isoforms in the tested cell lines and the response of transcription variants of the leptin receptor to leptin. Furthermore, we assessed the effects of leptin on the proliferation rate of the studied cells.

Only scanty data are available on the expression of leptin receptor in human normal prostate and prostate cancer cell lines. As mentioned earlier, two functional leptin receptor isoforms (huOB-R and huB219.3) were found in DU145, PC3, and LNCaP-FGC cell lines (30). Furthermore, expression of huOb-Ra and huOb-Rb was reported in DU145 and PC3 lines (31). In these studies, identical primers were used and described as a primers for huB219.3 (30) and OB-Ra (31). In their studies, expression of these leptin receptor isoforms was found in DU145, PC3, and LNCaP cell lines. Comparing the binding of these primers to the current isoforms of the leptin receptor gene (Fig. 1) indicates that these primers amplify variants 3 and/or 6 of receptor isoforms (as described in the present study). Furthermore, the primer for huOB-Rb applied by Somasundar et al (31) amplifies only a fragment of the single exon specific to isoform 1 . Therefore this design did not reduce the risk of false-positive amplification from genomic DNA. On the other hand, in a study by Onuma et al (30), exons spinning primers designed for huObR bound to specific exon of variant 1 of the leptin receptor. They found this expression in the LNCaP cell line; however, in the present study we were not able to confirm their finding. Onuma et al (30) also studied expression of the isoform huB219.1 of the leptin receptor gene. Applied primers are specific for variants 2 and 4. Expression of these variants was very high in $\mathrm{LNCaP}$ cells. In the present study, application of the various primers revealed that in the LNCaP cell line expression of only variant 2 of the leptin receptor gene was present (Table III). Furthermore, in the study by Onuma et al (30), the primers used for demonstration of huB219.2 were highly specific for variant 5 of the leptin receptor gene. On the basis of agarose gel electrophoresis data they found low expression levels of this isoform in the $\mathrm{LNCaP}$ cell line, the highest expression in DU145 and no expression in PC3 cells. In the present study by means of qPCR, we were not able to demonstrate expression of isoform 5 in all studied cell lines. However, as pointed above, a positive reaction for this isoform was found in human adrenal glands. Furthermore, in the study of Onuma et al (30) huB219.3 expression was found in DU145 and PC3 cells, and only very low expression was noted in the LNCaP cells. The same primers in a study by Somasundar et al (31), described as specific for huOb-Ra, 

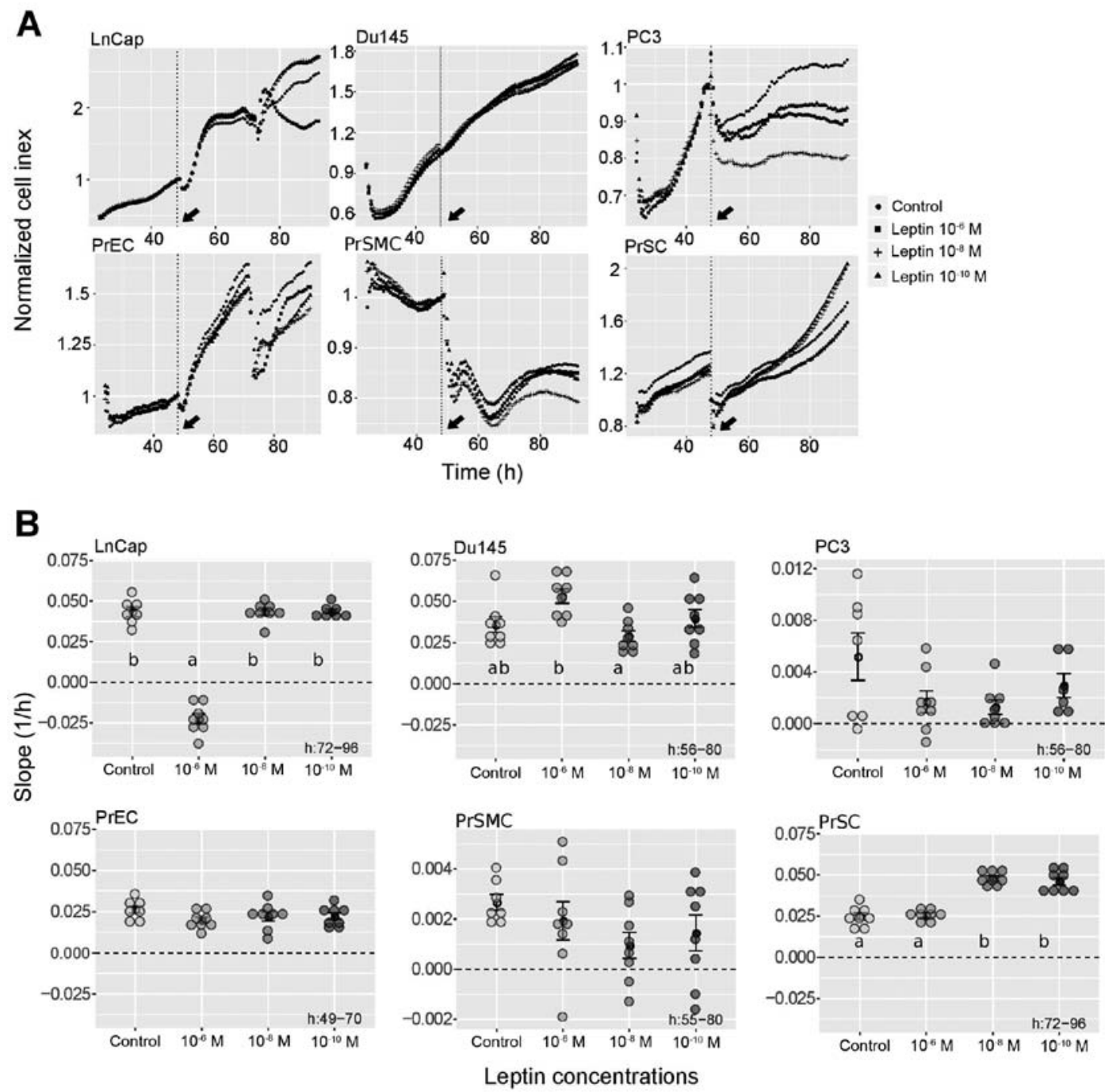

Figure 7. Effects of leptin on the proliferative activity of cultured human normal prostate and prostate cancer cell lines. (A) Normalized RTCA chart plot (cell index, recorded every $15 \mathrm{~min}$ ) in which points are marked every $45 \mathrm{~min}$. (B) Effects of leptin on slope values of proliferation rates of cultured human normal prostate and prostate cancer cell lines. The human prostate cancer cell lines: DU145, LNCaP, PC3. The human normal prostate cell lines: PrEC (prostate epithelial cells), PrSC (prostate stromal cells) and PrSMC (prostate smooth muscle cells). At $48 \mathrm{~h}$ of culture, leptin at concentrations $1 \times 10^{-6}, 1 \times 10^{-8}$ and $1 \times 10^{-10} \mathrm{M}$ was added - black arrows. Cells were incubated for at least $70 \mathrm{~h}$. From RTCA software, the slope values of proliferation rates were extracted at times of exponential growth of the control (no leptin addition) groups, as indicated with appropriate figures (h). (B) Each circle represents one cell culture. Means \pm SEM are shown. There were no statistically significant differences between group means as determined by one-way ANOVA for $\mathrm{PC} 3(\mathrm{P}=0.0806), \mathrm{PrEC}(\mathrm{P}=0.308)$ and PrSMC $(\mathrm{P}=0.283)$ cell lines. In the remaining cell lines, groups sharing the same letter were not significantly different according to Tukey's HSD test.

provided transcripts in DU145 and PC3 cells. However, in relation to actual nomenclature, applied primers may demonstrate variants 3 and/or 6 of leptin receptor isoforms. Our study did not reveal expression of isoform 6 in all analyzed cell lines; therefore, observed expression in their study may be connected with variant 3 of the leptin receptor.

Analysis of the literature indicates that only one publication contains data on the relationship between leptin and leptin receptor expression in human prostate cancer cell lines. By densitometry of agarose separated PCR products Somasundar et al (31) demonstrated that during $48 \mathrm{~h}$ of culture in serum-free medium, leptin did not alter the expression of the huOB-Ra isoform in DU145 cells, while in the PC3 cell line expression of this isoform was significantly increased. As it follows from the above analysis, their primers for huOB-Ra recognized variants 3 and/or 6 of leptin receptor isoforms. In the case of the huOB-Rb isoform, leptin did not change expres- sion of this gene in the DU145 cells and notably increased it in the PC3 cell line. According to the recent nomenclature, huOB-Rb is called variant 1 of the leptin receptor gene. In our study we observed a differential effect of leptin on the expression of leptin receptor isoforms in the studied cells. Observed effects were dependent mainly on leptin concentrations. In our study, leptin stimulated expression of leptin receptor variant 1 only in the PrSC cell line (at a concentration of $10^{-10} \mathrm{M}$ ). Expression levels of variants 2 and 4 of the leptin receptor were suppressed by leptin in the DU145 and PrEC cell lines and opposite effects were observed in the PrSC cells. As far as leptin variants 3 and 6 are concerned, leptin inhibited their expression in PrSMC cells and stimulated it in PrSC cells. Thus, our study showed that among the tested cell lines, leptin exerted the highest stimulatory effect on the expression of its receptor isoforms in PrSC cells. In the other cell lines, the effects of leptin on the expression of its receptor isoforms 
did not show any regularity. Recently, Noda et al (38) demonstrated that long-term exposure to leptin (28 days) increased ObR (leptin receptor) expression in the LNCaP, DU145 and PC3 cell lines. In this study, ObR was demonstrated by western blot analysis with polyclonal rabbit antibodies against human ObR (Sigma-Aldrich). However, these data are not sufficient to identify the specific variant of the leptin receptor.

In addition, data concerning the effects of leptin on the proliferation of human prostate cancer cell lines are controversial. By means of ${ }^{3} \mathrm{H}$-thymidine incorporation and MTT assay, Onuma et al (30) demonstrated that in serum-free medium leptin stimulated cell proliferation specifically in androgenindependent DU145 and PC3 prostate cancer cells but not in androgen-dependent LNCaP-FGC cells, although both cell types express functional leptin receptor isoforms. Similar results (by means of MTT assay) were observed in DU145 and PC3 cells cultured in FBS-containing culture medium $(31,39)$. By means of MTT assay, the stimulatory effect of leptin on the growth of DU145 cells was also observed by Bub et al (40). Recently Noda et al (38) demonstrated that a 48-h exposure to leptin did not affect the growth of LNCaP, DU145 and PC3, cells as assessed by WST- 8 assay. However, after a 28-day incubation with leptin, a notable increase in growth in all tested cell lines was found.

In the present study, using the RTCA platform, we examined the effects of leptin on the proliferation of LNCaP, DU145, PC3, PrEC, PrSMC and PrSC cell lines in the exponential phase of growth. As documented by changes in the proliferation slope, leptin inhibited the proliferation of LNCaP cells, stimulated growth of PrSC cells and had no effect on DU145, PC3, PrEC and PrSMC cells. A markedly pronounced stimulatory effect of leptin on proliferative activity was observed in the PrSC cell line. In the available literature, we did not encounter data concerning the effect of leptin on the proliferation of human normal prostate cell lines. Therefore, this observation appears to be extremely important, as it may explain the increased incidence of benign prostatic hyperplasia in obese patients with elevated blood leptin levels.

Considering the relationships between mitogenic action of leptin and expression of leptin receptor isoforms in DU145 and PC3 cell lines, Somasundar et al (31) suggested that mitogenic leptin effects are not a consequence of altered receptor isoform expression. It should be emphasized that in our study, the level of expression of leptin receptor isoforms was examined $48 \mathrm{~h}$ after leptin administration, while the 'proliferation slope' was evaluated after exposure of cells to leptin during the exponential growth phase (see Fig. 7B for details). In this situation, changes in the expression level of leptin receptor isoforms can not be ruled out [Noda et al (38)]. Thus, our data on the degree of expression of the leptin receptor isoforms analyzed reflect the condition after $48 \mathrm{~h}$ after leptin administration, which does not exclude changes in their expression level during subsequent incubation periods (corresponding to the proliferation slope). Our results also indicated no correlation between the level of expression of individual leptin receptor isoforms and the mitogenic effect of leptin protein. The analysis of our data suggest, however, that in prostatic cells which are deficient in leptin receptor variant 1 , leptin rather inhibits the mitogenic activity while in cells expressing this variant rather stimulates this activity or does not change this parameter.
Thus, the present study demonstrated that in all tested human normal prostate and prostate cancer cell lines (LNCaP, DU145, PC3, PrEC, PrSMC and PrSC) transcription variants 4,5 and 6 of the leptin receptor were not expressed. Leptin receptor transcription variants 1,2 and 3 showed differential expression, all of them present in the PC3, PrEC and PrSC cell lines. Our data also suggest that the stimulating effects of leptin on proliferative activity of the studied cell lines require the expression of leptin receptor variant 1 in the affected cells.

\section{Acknowledgements}

The study was supported by grant no. 2011/03/N/NZ3/06095 from the National Science Center, Krakow, Poland.

\section{References}

1. Bergström A, Pisani P, Tenet V, Wolk A and Adami HO: Overweight as an avoidable cause of cancer in Europe. Int $\mathbf{J}$ Cancer 91: 421-430, 2001

2. Hsing AW, Chua S Jr, Gao YT, Gentzschein E, Chang L, Deng J and Stanczyk FZ: Prostate cancer risk and serum levels of insulin and leptin: A population-based study. J Natl Cancer Inst 93: 783-789, 2001.

3. Bray GA: The underlying basis for obesity: Relationship to cancer. J Nutr 132 (Suppl): S3451-S3455, 2002

4. Calle EE, Rodriguez C, Walker-Thurmond $\mathrm{K}$ and Thun MJ: Overweight, obesity, and mortality from cancer in a prospectively studied cohort of U.S. adults. N Engl J Med 348: 1625-1638, 2003.

5. Allott EH, Masko EM and Freedland SJ: Obesity and prostate cancer: Weighing the evidence. Eur Urol 63: 800-809, 2013.

6. Hoda MR, Mohammed N, Theil G, Fischer K and Fornara P: Obesity and prostate cancer. Role of adipocytokines and clinical implications. Urologe A 51: 1253-1260, 2012 (In German).

7. Hoda MR, Theil G, Mohammed N, Fischer K and Fornara P: The adipocyte-derived hormone leptin has proliferative actions on androgen-resistant prostate cancer cells linking obesity to advanced stages of prostate cancer. J Oncol 2012: 280386, 2012.

8. Cao Y and Giovannucci E: Obesity and prostate cancer. Recent Results Cancer Res 208: 137-153, 2016.

9. Patel SB, Reams GP, Spear RM, Freeman RH and Villarreal D: Leptin: Linking obesity, the metabolic syndrome, and cardiovascular disease. Curr Hypertens Rep 10: 131-137, 2008.

10. Kaur J: A comprehensive review on metabolic syndrome. Cardiol Res Pract 2014: 943162, 2014.

11. Mantzoros CS: The role of leptin in human obesity and disease: A review of current evidence. Ann Intern Med 130: 671-680, 1999.

12. Klok MD, Jakobsdottir S and Drent ML: The role of leptin and ghrelin in the regulation of food intake and body weight in humans: A review. Obes Rev 8: 21-34, 2007.

13. Halaas JL, Gajiwala KS, Maffei M, Cohen SL, Chait BT, Rabinowitz D, Lallone RL, Burley SK and Friedman JM: Weight-reducing effects of the plasma protein encoded by the obese gene. Science 269: 543-546, 1995.

14. Cummings DE and Foster KE: Ghrelin-leptin tango in bodyweight regulation. Gastroenterology 124: 1532-1535, 2003.

15. Konturek PC, Konturek JW, Cześnikiewicz-Guzik M, Brzozowski T, Sito E and Konturek SJ: Neuro-hormonal control of foodintake: Basic mechanisms and clinical implications. J Physiol Pharmacol 56 (Suppl 6): 5-25, 2005.

16. Perry B and Wang Y: Appetite regulation and weight control: The role of gut hormones. Nutr Diabetes 2: e26, 2012.

17. Zhang Y, Proenca R, Maffei M, Barone M, Leopold L and Friedman JM: Positional cloning of the mouse obese gene and its human homologue. Nature 372: 425-432, 1994.

18. Maffei M, Halaas J, Ravussin E, Pratley RE, Lee GH, Zhang Y, Fei H, Kim S, Lallone R, Ranganathan S, et al: Leptin levels in human and rodent: Measurement of plasma leptin and ob RNA in obese and weight-reduced subjects. Nat Med 1: 1155-1161, 1995.

19. Friedman JM and Halaas JL: Leptin and the regulation of body weight in mammals. Nature 395: 763-770, 1998.

20. Tartaglia LA, Dembski M, Weng X, Deng N, Culpepper J, Devos R, Richards GJ, Campfield LA, Clark FT, Deeds J, et al: Identification and expression cloning of a leptin receptor, OB-R. Cell 83: 1263-1271, 1995. 
21. Cioffi JA, Shafer AW, Zupancic TJ, Smith-Gbur J, Mikhail A, Platika D and Snodgrass HR: Novel B219/OB receptor isoforms: Possible role of leptin in hematopoiesis and reproduction. Nat Med 2: 585-589, 1996.

22. Ahima RS and Flier JS: Leptin. Annu Rev Physiol 62: 413-437, 2000.

23. Malendowicz W, Rucinski M, Macchi C, Spinazzi R, Ziolkowska A, Nussdorfer GG and Kwias Z: Leptin and leptin receptors in the prostate and seminal vesicles of the adult rat. Int J Mol Med 18: 615-618, 2006.

24. Maamra M, Bidlingmaier M, Postel-Vinay MC, Wu Z, Strasburger CJ and Ross RJ: Generation of human soluble leptin receptor by proteolytic cleavage of membrane-anchored receptors. Endocrinology 142: 4389-4393, 2001.

25. Ge H, Huang L, Pourbahrami T and Li C: Generation of soluble leptin receptor by ectodomain shedding of membrane-spanning receptors in vitro and in vivo. J Biol Chem 277: 45898-45903, 2002.

26. Schultz SC and Widmaier EP: Leptin receptors. In: Leptin. Castracane VD and Henson MC (eds). Vol. 25. Springer, Endocrine Updates, Heidelberg, pp11-31, 2007.

27. Wada N, Hirako S, Takenoya F, Kageyama H, Okabe M and Shioda S: Leptin and its receptors. J Chem Neuroanat 61-62: 191-199, 2014.

28. Stattin P, Söderberg S, Hallmans G, Bylund A, Kaaks R, Stenman UH, Bergh A and Olsson T: Leptin is associated with increased prostate cancer risk: A nested case-referent study. J Clin Endocrinol Metab 86: 1341-1345, 2001.

29. Malendowicz W and Kwias Z: Leptin receptor isoforms in benign prostatic hyperplasia $(\mathrm{BPH})$. $\mathrm{BPH}$ and prostate cancer - no association between plasma concentrations of leptin and prostate specific antigen (PSA). Cent European J Urol 62: 96-100, 2009.

30. Onuma M, Bub JD, Rummel TL and Iwamoto Y: Prostate cancer cell-adipocyte interaction: Leptin mediates androgenindependent prostate cancer cell proliferation through c-Jun NH2-terminal kinase. J Biol Chem 278: 42660-42667, 2003.

31. Somasundar P, Frankenberry KA, Skinner H, Vedula G, McFadden DW, Riggs D, Jackson B, Vangilder R, Hileman SM and Vona-Davis LC: Prostate cancer cell proliferation is influenced by leptin. J Surg Res 118: 71-82, 2004.
32. Paschke L, Rucinski M, Ziolkowska A, Zemleduch T, Malendowicz W, Kwias Z and Malendowicz LK: ZFP91 - a newly described gene potentially involved in prostate pathology. Pathol Oncol Res 20: 453-459, 2014

33. Szyszka M, Paschke L, Tyczewska M, Rucinski M, Grabowska P and Malendowicz LK: Lack of expression of preproorexin and orexin receptors genes in human normal and prostate cancer cell lines. Folia Histochem Cytobiol 53: 333-341, 2015.

34. Rucinski M, Albertin G, Spinazzi R, Ziolkowska A, Nussdorfer GG and Malendowicz LK: Cerebellin in the rat adrenal gland: Gene expression and effects of CER and (des-Ser1) CER on the secretion and growth of cultured adrenocortical cells. Int J Mol Med 15: 411-415, 2005.

35. Rucinski M, Ziolkowska A, Tyczewska M and Malendowicz LK: Expression of prepro-ghrelin and related receptor genes in the rat adrenal gland and evidences that ghrelin exerts a potent stimulating effect on corticosterone secretion by cultured rat adrenocortical cells. Peptides 30: 1448-1455, 2009.

36. Tyczewska M, Rucinski M,Ziolkowska A, Szyszka M, Trejter M, Hochol-Molenda A, Nowak KW and Malendowicz LK: Enucleation-induced rat adrenal gland regeneration: Expression profile of selected genes involved in control of adrenocortical cell proliferation. Int J Endocrinol 2014: 130359, 2014.

37. Markowska A, Belloni AS, Rucinski M, Parenti AR, Nardelli GB, Drews K, Nussdorfer GG and Malendowicz LK: Leptin and leptin receptor expression in the myometrium and uterine myomas: Is leptin involved in tumor development? Int J Oncol 27: 1505-1509, 2005.

38. Noda T, Kikugawa T, Tanji N, Miura N, Asai S, Higashiyama S and Yokoyama M: Long-term exposure to leptin enhances the growth of prostate cancer cells. Int J Oncol 46: 1535-1542, 2015.

39. Somasundar P, Yu AK, Vona-Davis L and McFadden DW: Differential effects of leptin on cancer in vitro. J Surg Res 113: 50-55, 2003.

40. Bub JD, Miyazaki T and Iwamoto Y: Adiponectin as a growth inhibitor in prostate cancer cells. Biochem Biophys Res Commun 340: 1158-1166, 2006. 